\title{
A complete methodology for the mechanical diagnosis of statue provided by innovative uses of 3D model \\ Application to the imperial marble statue of Alba-la-Romaine (France)
}

\author{
MARINE BAGNÉRIS ${ }^{\mathrm{a} *}$, FABIEN CHERBLANC ${ }^{\mathrm{b}}$, PHILIPPE BROMBLET ${ }^{\mathrm{c}}$, ELOI GATTET ${ }^{\mathrm{a}}$, \\ LÉONARD GÜGI ${ }^{a}$, NICOLAS NONYa, VINCENT MERCURIO ${ }^{c}$ and ANTHONY PAMART ${ }^{a}$ \\ a UMR 3495 MAP CNRS/MCC, Campus CNRS Joseph Aiguier - Bât. Z', 31 chemin Joseph Aiguier, \\ 13402 Marseille Cedex 20, France \\ b Laboratoire de Mécanique et Génie Civil (LMGC), Université de Montpellier, CNRS, Montpellier, \\ France. \\ ${ }^{\text {c }}$ CICRP Belle de Mai, 21 rue Guibal, 13003 Marseille, France.
}

\begin{abstract}
:
A multidisciplinary methodology is presented to assess the mechanical behaviour of a marble statue with complex fracture plans and localized cracks. Firstly, a 3D model is generated by photogrammetry. Its underlying geometrical data provide valuable insight for the physical characterisation and the numerical analysis. Indeed, the ultrasound analysis, which is usually impossible on such a complex shape, is achieved thanks to the accurate measures of distance between transmitter and receiver obtained from the 3D geometrical model. Finally, an innovative use of FEM/DEM analysis is proposed to evaluate the mechanical relevance of a non-destructive basing system. Reflecting the advances of this collective work, the resulting pedestal solution is non-conventional since it is safe, not invasive and totally reversible. A particular attention is paid to use mainly open-source numerical tools from 3D acquisition through mechanical analysis in order to enable the reproducibility of the process.
\end{abstract}

Keywords: White marble statue, Photogrammetry, 3D model, Ultrasonic velocity, Finite Element Method, Discrete Element Method. 


\section{Research aims:}

Innovative fields of competence are continuously requested by conservation and restoration in order to enrich the body of heritage and archaeological knowledge. Nowadays, advances in methods and tools dedicated to numerical modelling and physical characterisations broadly contribute to enlighten the diagnosis analysis of historical artworks. However, 3D models provided by photogrammetry or laser scanning are still not fully exploited by the practitioners to perform further insights into a computeraided restoration process. This paper aims at presenting how an accurate 3D geometrical description of an artwork can be used to carry out an ultrasonic analysis and an advanced numerical computation, respectively performed to evaluate the damage level of material and to estimate the mechanical stresses generated by a basing system without intrusive bond. Above the proposed methodology, the objective is to use open-source numerical tools from 3D acquisition through mechanical analysis in order to enable the reproducibility of the process.

\section{Introduction:}

By paying attention to the history [1,2], innovative fields of competence are continuously requested by conservation and restoration in order to enrich the body of heritage and archaeological knowledge. Nowadays, advances in methods and tools dedicated to numerical modelling and physical characterisations broadly contribute to enlighten the diagnosis analysis of historical artworks. Photogrammetry and laser scanning allow the generation of realistic 3D models that have been mainly used to constitute accurate documentations of architectures and heritages [3-5], web-based visualization systems [6,7] or virtual reality and multimedia museum exhibitions. Above their fascinating visual interests, such 3D models contain geometrical data which are still not fully exploited by the practitioners to perform further insights into a computer-aided restoration process. The meshes generated from the point clouds have been used to virtually assemble dismounted historic buildings [8] or statues $[9,10]$ and to simulate their mechanical behaviour by Finite Element Method (FEM). For 
instance, the diagnosis of the lesions and stability of Michelangelo’s David have been conducted thanks to FEM applied on the digital model of the statue [11]. The authors assess the risk of crack propagation under both static and dynamic conditions, although so far the seismic response analysis was limited to a truss model to lower the computational cost. Later, dynamic analysis have been performed on 3D model to evaluate the seismic responses of statues and the structural ability to withstand road transport vibrations [12,13]. A third potentiality consists in virtually fitting the restoration process in order to visualize the path of the pins inside the volume [9]. Reassembly of fractured stones relies mainly on two techniques which consist in drilling into the substrate and installing pins and/or gluing the contact surfaces by an adhesive. The former is a risky task since the restorer has to optimise the material thickness between the drilling and the skin to avoid any critical weakening of the artwork [14]. The mechanical efficiency of these restoration practices on the global stability and the local resistance of stone can thus be assessed numerically [13,15-17].

Numerical models and results have to be scaled by physical data (density, porosity, mechanical strengths, Young modulus ...) obtained experimentally. Such data are generally measured by NDT techniques due to the patrimonial value of the studied artworks. Indeed, ultrasonic analysis is particularly reliable on marble to evaluate the damage level of basic architectural elements like gravestone [18] or column [19]. Since the accurate evaluation of the distance between transducers is required to calculate the ultrasound velocity, practical applications have been carried out only with simple and planar geometries [18,19]. Measurements on complex geometries are quite challenging and mostly estimated to perform the ultrasound analysis [20]. The depth of surface cracks on marble artworks can also be assessed using ultrasonic measurements [21] while difficulties to locate precisely the transducers and determine the distance travelled by ultrasound is still a drawback of in situ experiments.

This article presents a complete methodology to face general issues related to the exhibition of an 
ancient marble statue on a pedestal. To illustrate its reliability, the methodology is applied to the mechanical diagnosis of a Roman marble statue found in Alba-la-Romaine (France) with the aim of designing an appropriate fully reversible base avoiding any material damage and optimizing the legibility of the sculpture. Main stages of the analysis rely on using data from the 3D model: from the initial investigation with historians about the original posture, to the ultrasonic material characterisation and the simulation of the mechanical behaviour of the statue on its base.

\section{Materials:}

\subsection{Statue}

The marble statue was discovered in a small sanctuary (sanctuary of Bagnols, France) during excavation of the Roman city in 1992 [22]. It was found into the ground, lying on its back, all the members and the head being broken. Those broken parts (arms, legs...) might have been used for lime production, which could explain that they are still missing despite the large site excavation. The broken statue is $1.5 \mathrm{~m}$ high and weighs $498 \mathrm{~kg}$. It describes a naked athletic male with a military coat (paludamentum) on his left shoulder. Dated between 117 and 138 AD, it should preferentially represent Trajan Emperor and thus constitutes a rare testimony of the imperial cult attested by the quality of the execution and its iconographic, stylistic and technical characteristics.

The statue has been cleaned and some earth deposits have been removed just after its uncovering. The marble surface is in good condition, gently eroded and aged but without any visible feature of degradation excepted a coarse scratching mark on its belly and chest. Few thin cracks are noticeable close to the fracture planes of head and left arm. Two parallel cracks of ten centimetres length located in the left groin could be problematic when the statue is standing. The left leg has been broken above the knee and the right one at mid-thigh. The fracture planes of both legs are far from flat but describe sharp angles that end in acute bevel. Because of these complex fractures planes and the cracks on the left groin, the statue had never been stood up and positioned on a base. 


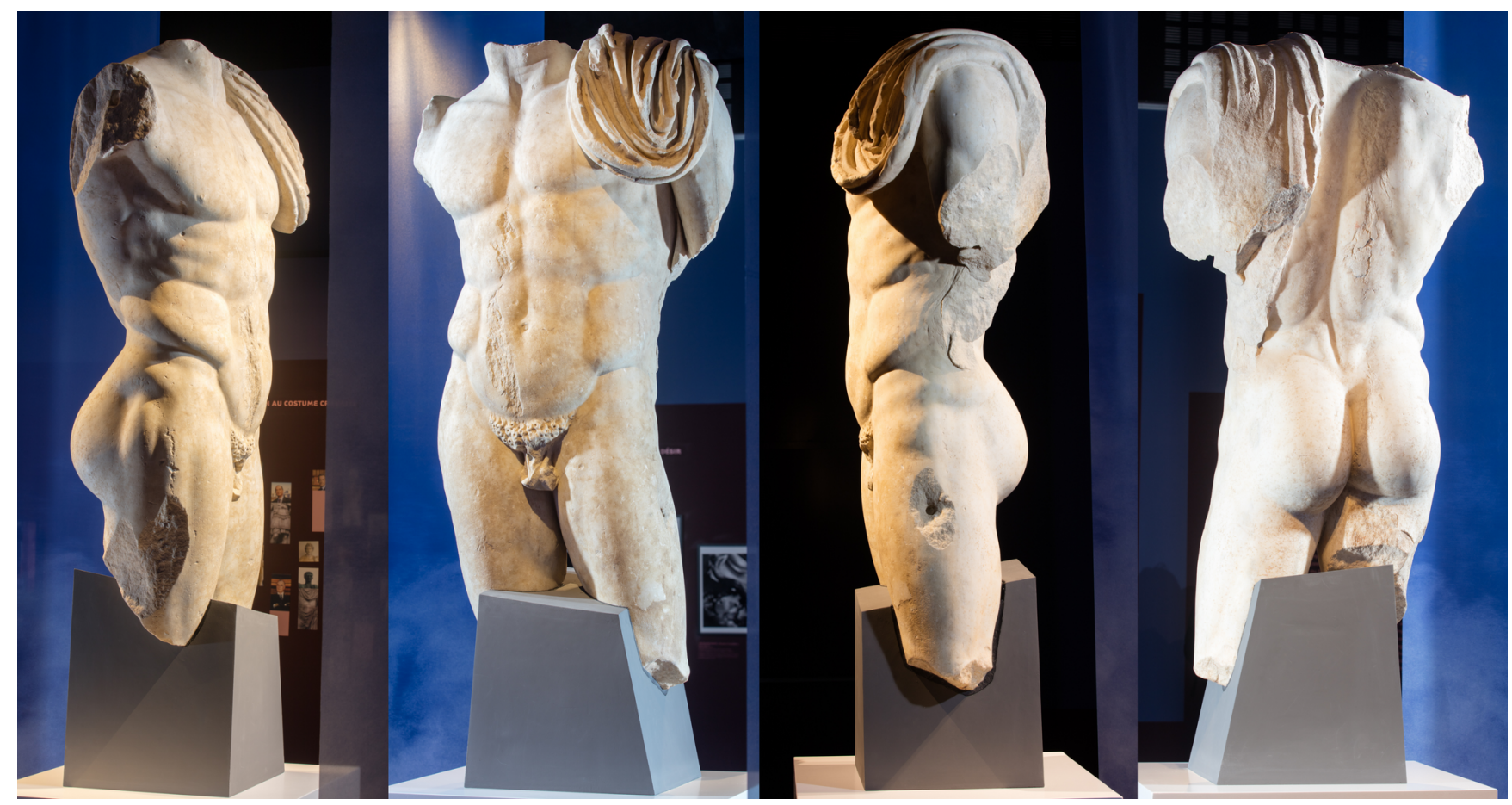

Figure 1: Final presentation of the statue showing the basing principle (pictures Philippe Fournier).

\subsection{Marble}

The white marble is a fine grained one with a maximum grain size (MGS) of 2mm. Many millimetric greenish veins enriched in phyllosilicates (mica, chlorites) cross the statue vertically, underlining the lineation of this marble. A perpendicular and irregular vein of large calcite crystals crosses the statue just below its chest. Cathodoluminescence and isotopic analyses $\left(\delta{ }^{18} \mathrm{O} /{ }^{16} \mathrm{O}=-4.72\right.$ an $\left.\delta{ }^{13} \mathrm{C} /{ }^{12} \mathrm{C}=2.50\right)$ had been performed in 1994 by V. Barbin just after the discovering of the statue. It allowed to identify the marble as a Pentelic one (unpublished report, Reims University). Macro features such as greenish veinlets, maximum grain size and petrographic features observed on a thin section and compared to reference thin sections confirmed the Pentelic provenance: mean diameter around $0.5 \mathrm{~mm}$, curved to embayed crystal boundaries, mosaic and lineated fabric [23].

\subsection{Basing system}

A non-intrusive and completely reversible basing system is chosen. The principle is to hold the statue on the internal part of the legs by means of a distributed contact surface over its external face without 
any chemical or mechanical bond (Fig. 1). Only the geometrical shape of this contact surface ensures the stability of the statue. The material of the base must meet 3 criteria:

- a comparable rigidity with respect to the marble to obtain a rigid behaviour of the whole assembly,

- a satisfying tensile and compressive strength to withstand external and accidental loadings,

- an ability to shape the complex geometry of the statue which is maintained without any additional support, pin or bond.

An alkali-resistant glass fibre reinforced concrete has been chosen to fulfil these requirements, the mechanical properties are detailed in Tab. 1. A thin interface layer of epoxy resin, softer than the stone and the concrete, is introduced between the statue and the base to avoid localised punching damage and allow a better contact stresses distribution.

The underlying deontological and aesthetic criteria leading to this choice are beyond the scope of this paper and will not be discussed here. Thus, the objectives are to propose a methodology to assist the conceptual design of the basing system and to validate its mechanical relevance.

\section{Methodology}

\subsection{D Model}

The MicMac photogrammetric open-source suite of tools [24,25] is used to generate the point cloud. Accurate and effective 3D reconstruction of heritage objects depends fundamentally on best practices of the image-based acquisition protocols and the understanding of the software parameters [26,27]. To validate the whole pipeline, several benchmarks evidenced the metrological performance of MicMac tools [5,28]. A set of 250 images was acquired with a calibrated Nikon D800E (36 mega-pixels) mounting $24 \mathrm{~mm}$ and $50 \mathrm{~mm}$ lenses. The statue was lying on a pallet in the archaeological warehouse. 

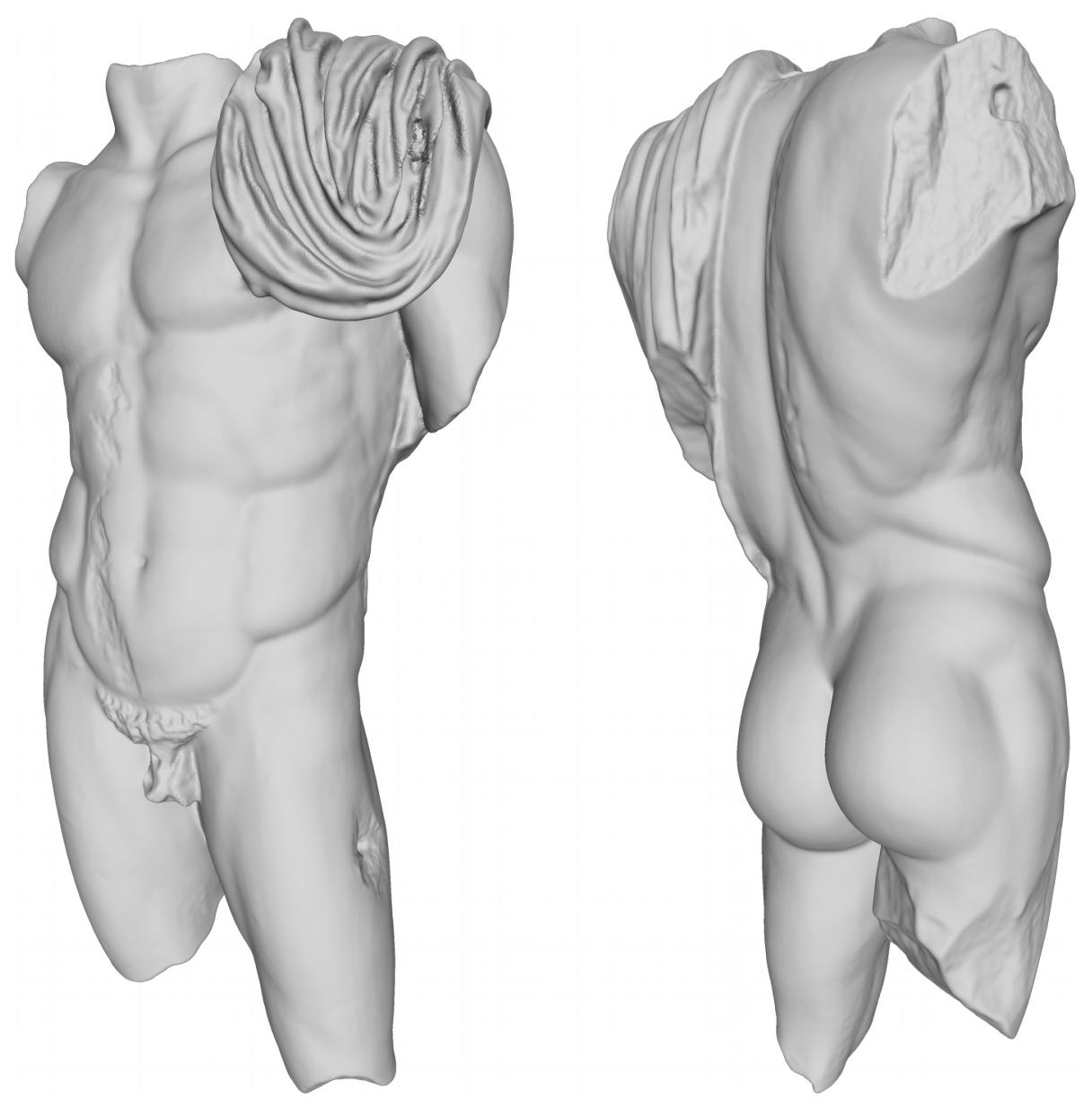

Figure 2: 3D geometrical modelling of the statue (visualization with Meshlab).

Consequently, the statue has been turned over to perform the image acquisition in two stages, i.e. the front and the back. Convergent images are needed to shoot complex hidden details and an overlap around $80 \%$ is required to ensure the automatic detection of tie points for the image orientation. Then, the "back" acquisition is properly oriented onto the "front" one according to their common side points. As the next stages of the analysis rely on the quantitative accuracy, some graduated rulers placed around the statue aim at scaling the model. Such a scaling operation is provided by the photogrammetric pipeline. A dense point cloud was finally extracted from the correlation procedure between master images and all the neighbourhood images. The underlying multi-scale, multi-resolution and pyramidal matching algorithm based on an energy minimization approach is addressed in [25]. An accuracy level below $5 \mathrm{~mm}$ has been a posteriori checked by comparative measurements between the 
real statue and its virtual clone. Since the point cloud does not constitute a geometrical entity, a surfacic mesh must be suitably generated using MeshLab [29] (Fig. 2). Indeed, a very refined mesh might contain a lot of details which are not necessarily relevant for the mechanical simulation. As further explained in section 4.4, the statue and its base are modelled by two distinct objects in interaction by a contact law. The number of contact points directly depends on the number of mesh elements. As the calculation of the reaction force at each contact point relies on a non-linear numerical procedure, a detailed 3D model can be prohibitive in terms of computation cost without bringing substantial information on the behaviour. On the contrary, a refined mesh is required to study the posture restoration or to design the basing system which shapes the legs of the statue.

\subsection{Ultrasonic evaluation}

Ultrasound velocity measurements were carried out on the statue to evaluate the cohesion and homogeneity of the marble. This method is well known and very efficient to investigate the state of white marbles ranging them into 5 classes from fresh unweathered marble (class I) to disintegrated and porous material (class V) according to the ultrasonic velocity [20,30,31]. The experimental campaign was carried out with a transportable ultrasonic equipment (Au2000, CEBTP) working at $54 \mathrm{kHz}$ with an assumed accuracy of $\pm 10 \%$. The calibration of the device was controlled with a reference resin cylindrical bar. Pieces of latex were used to improve the contact between the transmitter and the marble surface. The delay induced by the interposition of these latex pieces was subtracted afterwards from each measurement to obtain the effective time of flight (TOF) through the statue. 72 positions were investigated all over the statue and at least 3 measurements were performed and averaged for each position of the sensors.

By using a ruler or a compass, the accurate measure of the distance between the transmitter and the receiver is nearly impossible on a 3D complex shape. This difficulty has been overcome by relying on the 3D geometrical model of the statue. After each measurement, small numbered stickers are put on 
the marble surface to materialize the position of both emitter and receiver. Actually, the photogrammetric acquisition detailed in previous section has been done at the end of the ultrasonic auscultation. The main advantage of photogrammetry technique is that, besides providing the 3D position of each pixel, it also gives its colour allowing to identify the texture. The localization of each sticker is then possible on the 3D model to get its coordinates with a $5 \mathrm{~mm}$ accuracy. Thus, the minimal distance travelled by ultrasonic waves is determined for each measure by associating emitter and receiver $3 \mathrm{D}$ coordinates.

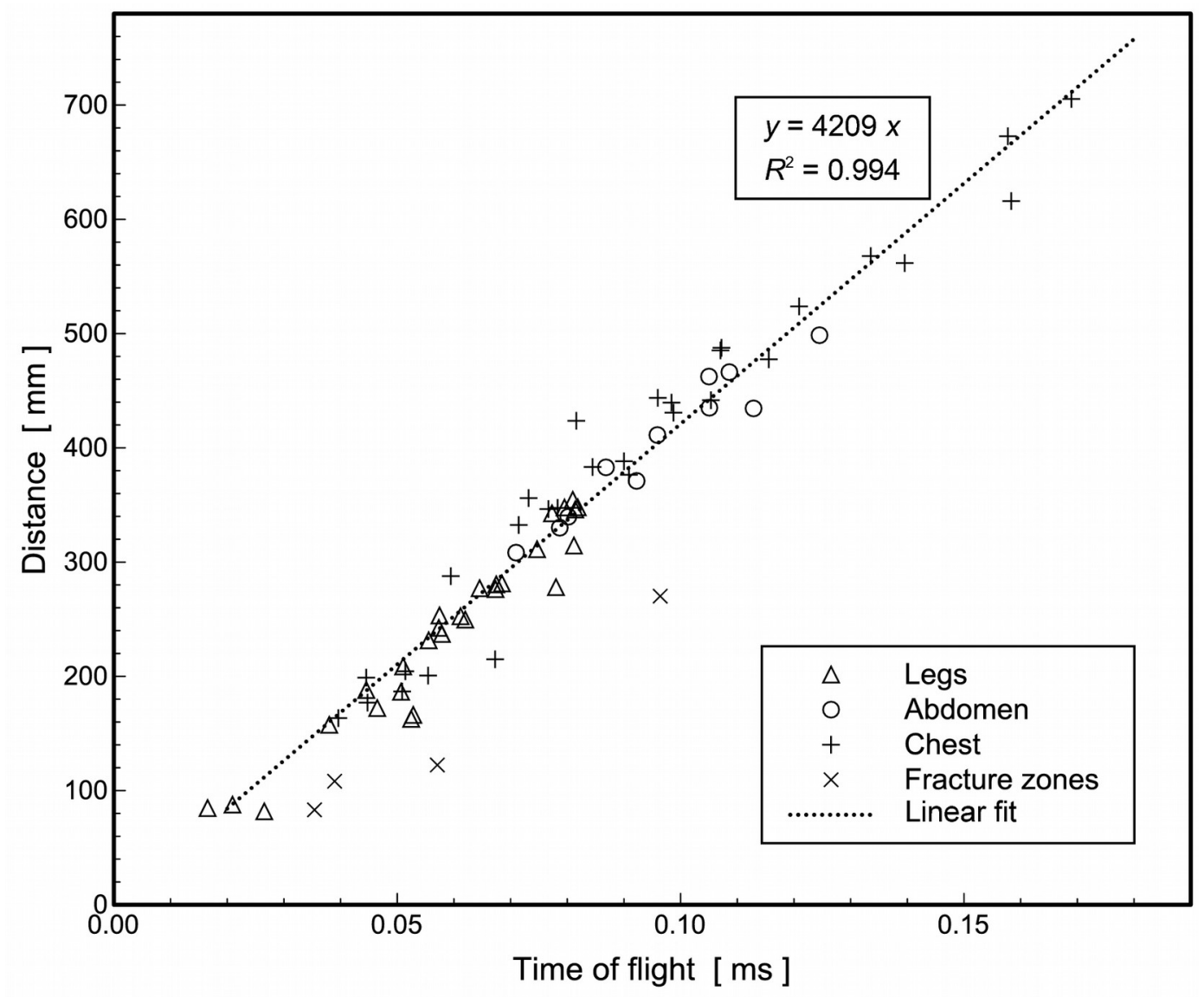

Figure 3: Experimental ultrasound velocity measurements. Travel distance as a function of the time of flight in different zones of the statue.

When all the measured TOF are plotted versus the distance between the transmitter and the receiver (Fig. 3), 4 measures exhibit lower ultrasound velocities (from 2145 to $2803 \mathrm{~m} / \mathrm{s}$ ). These measures have been carried out through the visible fractures, in the left groin and close to the left arm. If these visible 
fracture zones are excluded, a very good linearity is observed $\left(\mathrm{R}^{2}=0.99\right)$. This indicates that the marble is very homogeneous whatever the zone under investigation, legs, abdomen or chest. The whole set of measurements can be represented on the 3D geometrical model providing a much better visualization of results (Fig. 4).

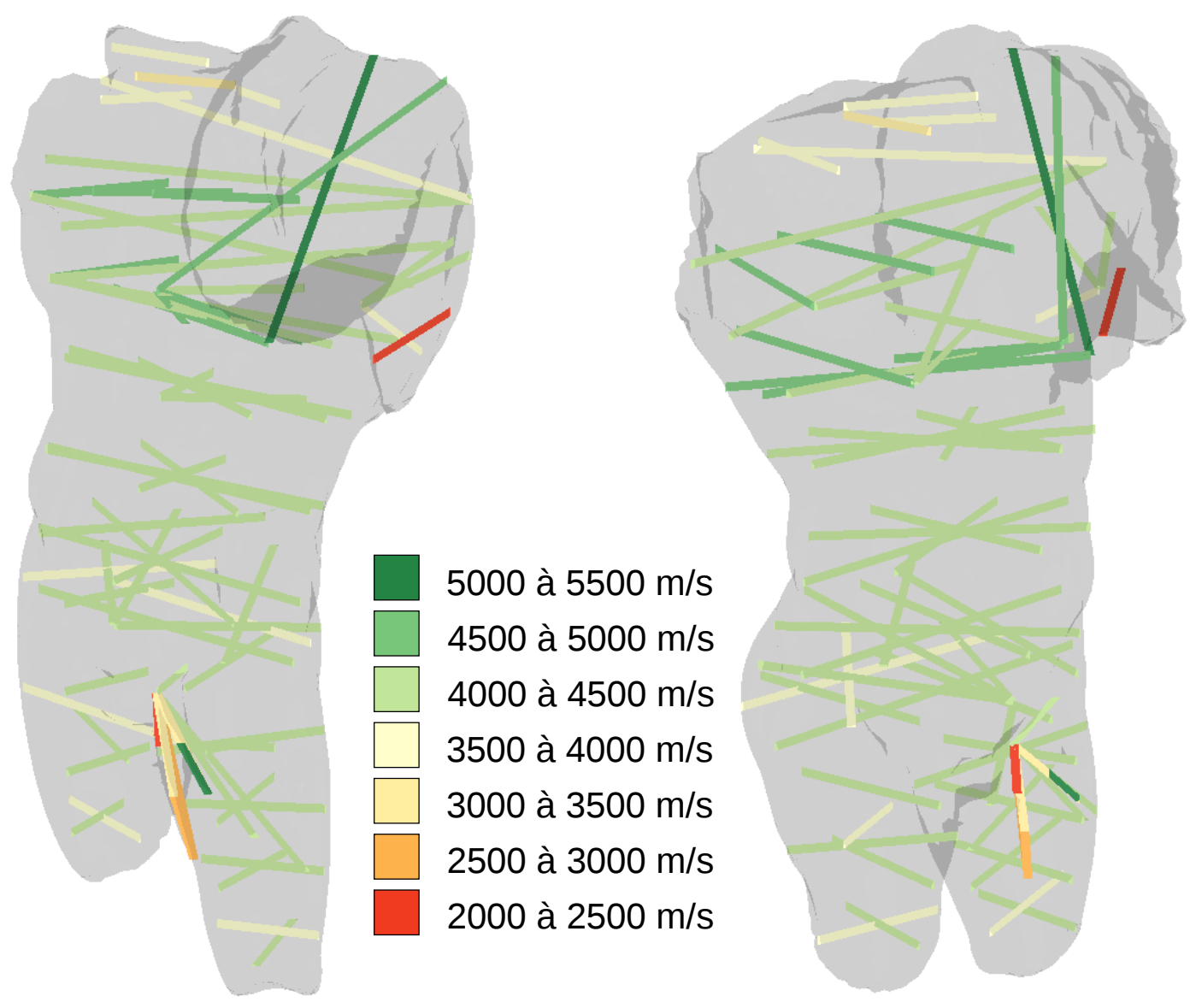

Figure 4: 3D representation of the ultrasound velocity measurements inside the statue (visualization with Paraview).

Finally, with a mean US velocity of 4209 +/- $401 \mathrm{~m} / \mathrm{s}$, this marble belongs to the class II (3000 to 5000 $\mathrm{m} / \mathrm{s}$ ) within the damage classification of white marbles. Just an increasing porosity (0.5 to $1.3 \%$ ) distinguishes this class II from fresh white marble (class I, porosity $<0.5 \%$ ).

In addition to this global auscultation, an evaluation of the depth of the crack located at the left groin is in progress using a YAG infrared laser beam as receiver. The results of this complementary approach are under process to be published soon. 


\subsection{Posture restoration}

The curators pay a particular attention to exhibit the statue in accordance with its original posture. Despite the missing parts, the historians based two hypothesis on comparative studies with similar Roman statues: the right standing leg was straight and the right foot lays firmly on the ground. A numerical puppet of a whole body is precisely designed with the aesthetic and anatomic characteristics of the statue using $3 \mathrm{ds}-\mathrm{Max}{ }^{\circledR}$. Starting from a neutral position, the puppet's skeleton is then slightly moved on by inclining the pelvis and the spinal column, adapting the shoulders and rotating the head in order to fit the 3D model of the existing part. Then, the parts of the puppet which are shared with the 3D model are frozen while the members can be animated to investigate the complete posture. In this phase, the computer-aided manipulation of the virtual puppet allows adjusting the spatial position and orientation of the 3D model consistent with anatomic constraints (Fig. 5).
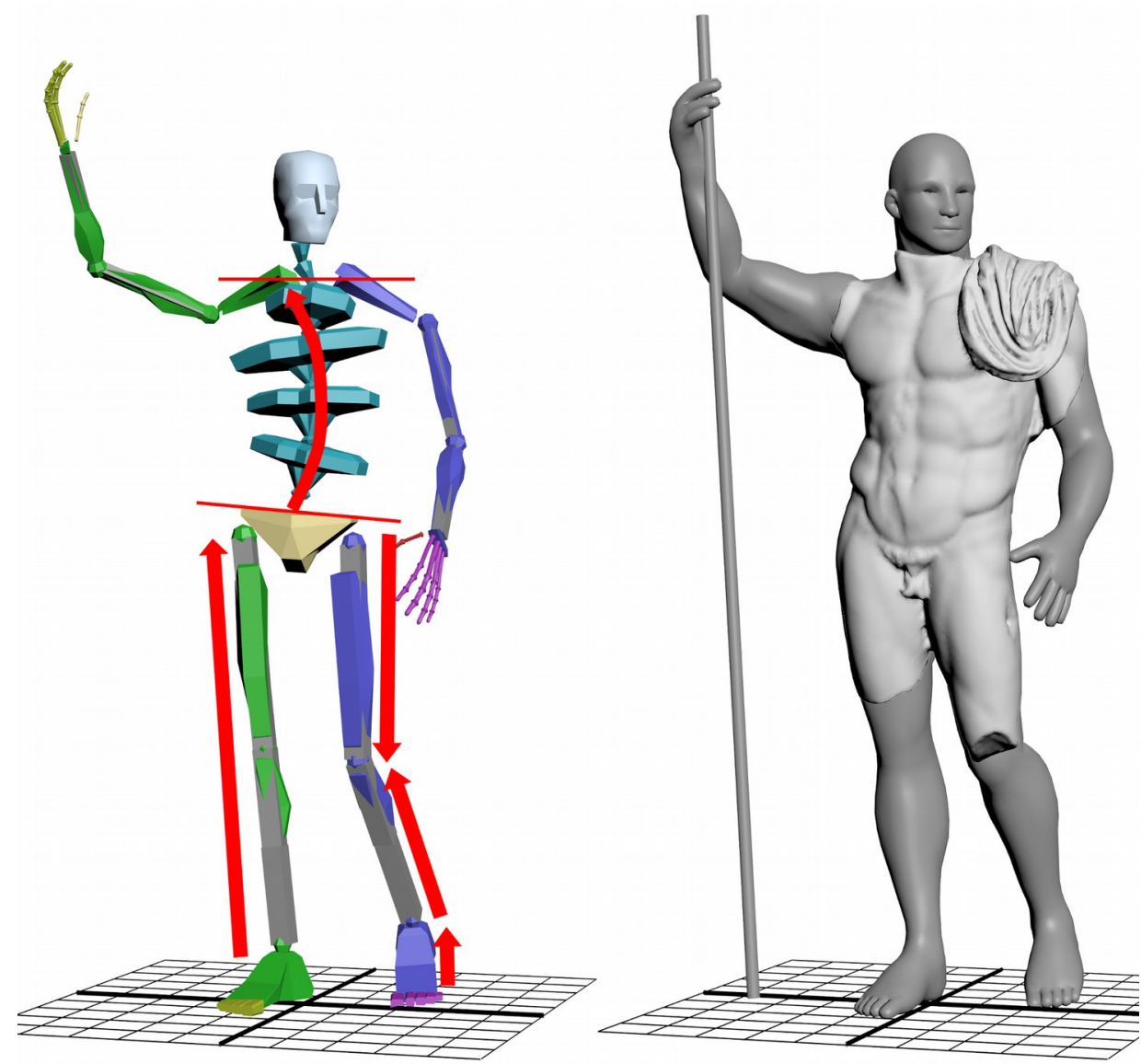

Figure 5: Animated puppet based on the anatomical description of the statue. 
Following the expertise of the historians, the right arm held up and leant on a lance. The paludamentum, the Roman general's coat, which is placed on the left shoulder, coiled around the left arm to fall on the outer side. These morphological arrangements of the artwork have been confirmed by this numerical approach. However, a last hypothesis supposing that the left hand maintained a sword could not be validated because of the lack of clue.

The 3D model is now spatially oriented. This stage, validated in close collaboration with the historians, is crucial for the next phases. Indeed, any basing principle depends on the genuine posture of the statue.

\subsection{Mechanical analysis}

As presented in section 3.3, the basing system consists of surfacic support on the internal part of the legs (Fig. 1). Without any chemical or mechanical bond, its mechanical integrity depends on the shape and the distribution of contact area between the statue and the base. Thus, the mechanical simulation must handle contact interactions between non-convex and complex surfaces. This challenging task is performed with the open-source software LMGC90 [32,33] implementing the Non-Smooth Contact Dynamics theory [34]. By coupling DEM (Discrete Element Method) and FEM (Finite Element Method), this software is particularly dedicated to encompass the mechanical behaviour of collections of objects with various shapes, sizes and interaction laws.

The validation of the basing principle includes two issues. The first one concerns the overall stability of the statue when placed in its base and the second one focuses on the mechanical stresses generated inside the statue and the base materials. The geometrical model of the base is generated by subtracting the mesh of the statue from a prismatic block shape, according to a Boolean operation performed with the OpenCascade CAD module of the open-source platform Salome. This procedure ensures to preserve the spatial positioning of the statue determined in previous section. Then, a tetrahedral mesh is generated with Gmsh [35] to be introduced in numerical simulations (Fig. 6). As discussed in section 4.1, the mesh of the statue is generated from a sub-sampled point cloud in order to avoid prohibitive 
computation cost. The interaction between the statue and its base are computed on 1053 contact points, which is large enough to provide accurate results.

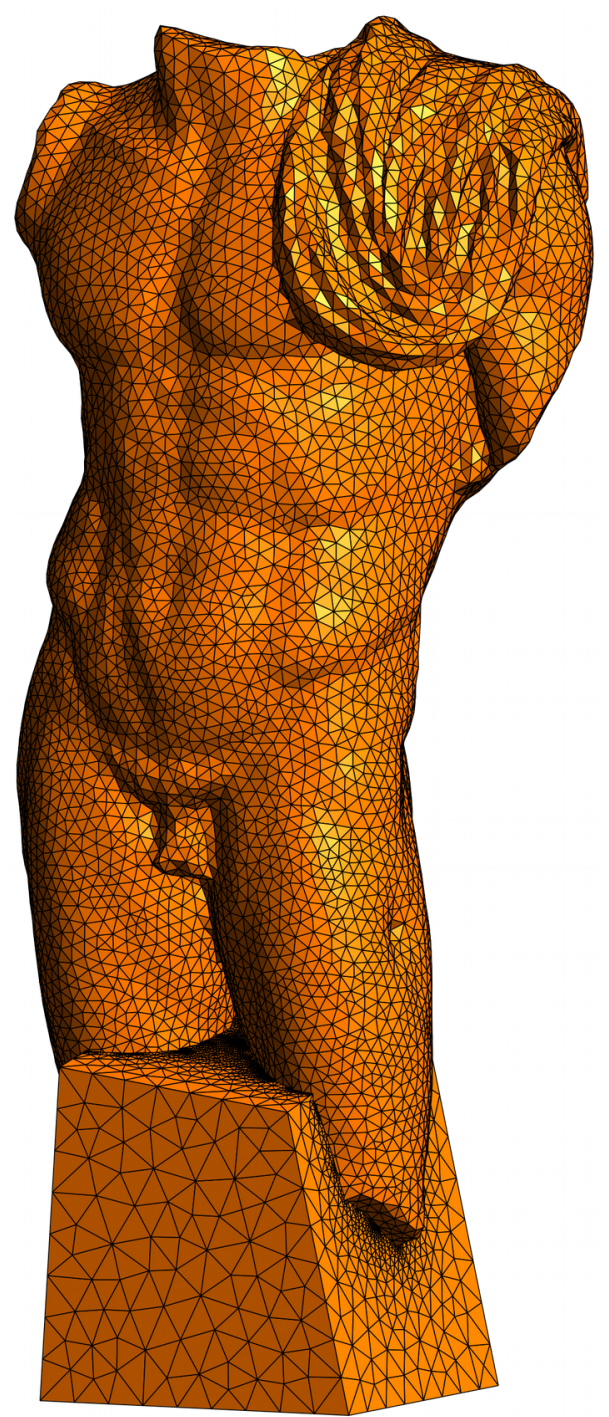

Figure 6: Numerical modelling of the statue and its base (visualization with Gmsh).

The physical properties of materials (Penteli marble for the statue, fibre reinforced concrete for the base and epoxy resin for the interface) are given in Tab. 1. Since Penteli marble has been widely used for building and sculpture, its mechanical characteristics have been thoroughly analysed in the literature [36-39]. Due to the natural heterogeneity and anisotropy of the material, a significant variability in mechanical characteristics is observed. Thus, the most critical values have been taken for numerical simulations. Furthermore, the interface is modelled through an elastic unilateral contact law, i.e. the 
normal reaction force is proportional to the interpenetration and vanishes when contact separates. In this case, the rigidity of the contact law represents the stiffness of the epoxy resin. The friction coefficient is null to remove the tangential part of reaction forces, i.e., this corresponds to the most critical case as it maximizes mechanical stresses inside the statue. The base is fixed to a steel frame through 4 pins to avoid sliding and rotating so that rigid conditions are imposed on the bottom of the base.

\begin{tabular}{|l|c|c|c|}
\hline & statue & interface & base \\
\hline Material & marble, class II & epoxy resin & $\begin{array}{c}\text { ultra-high performance } \\
\text { fibre-reinforced } \\
\text { concrete }\end{array}$ \\
\hline density [kg/m3] & 2800 & 2200 & 2340 \\
\hline Young modulus [GPa] & 45 & 6 & 30 \\
\hline Poisson's ratio & 0.20 & 110 & 0.20 \\
\hline $\begin{array}{l}\text { compressive strength } \\
\text { [MPa] }\end{array}$ & 90 & 40 & 90 \\
\hline tensile strength [MPa] & 5.3 & & 9 \\
\hline
\end{tabular}

Table 1: Physical properties of materials

The statue is exhibited inside a museum to be preserved from climatic conditions. However, since it is accessible to visitors, 4 loading cases has been considered in order to deal with security issues. The cases of a horizontal force of $1000 \mathrm{~N}$ applied above the gravity centre from front, rear, left or right directions are combined with the dead-load case.

First, the displacement and the distribution of contact pressure at the interface between the statue and the base are shown in Figs. $7 \& 8$ in the case of gravity load. While the supporting leg was originally the right one, the gravity centre is now shifted to the left, slightly backward, owing to the missing parts (arms, head and legs). Consequently, the maximal pressure arises under the left leg and is about 0.26 MPa. The other main contact surfaces are located under the right leg, on the bottom front and the top back of the left leg, in agreement with the location of the gravity centre. 


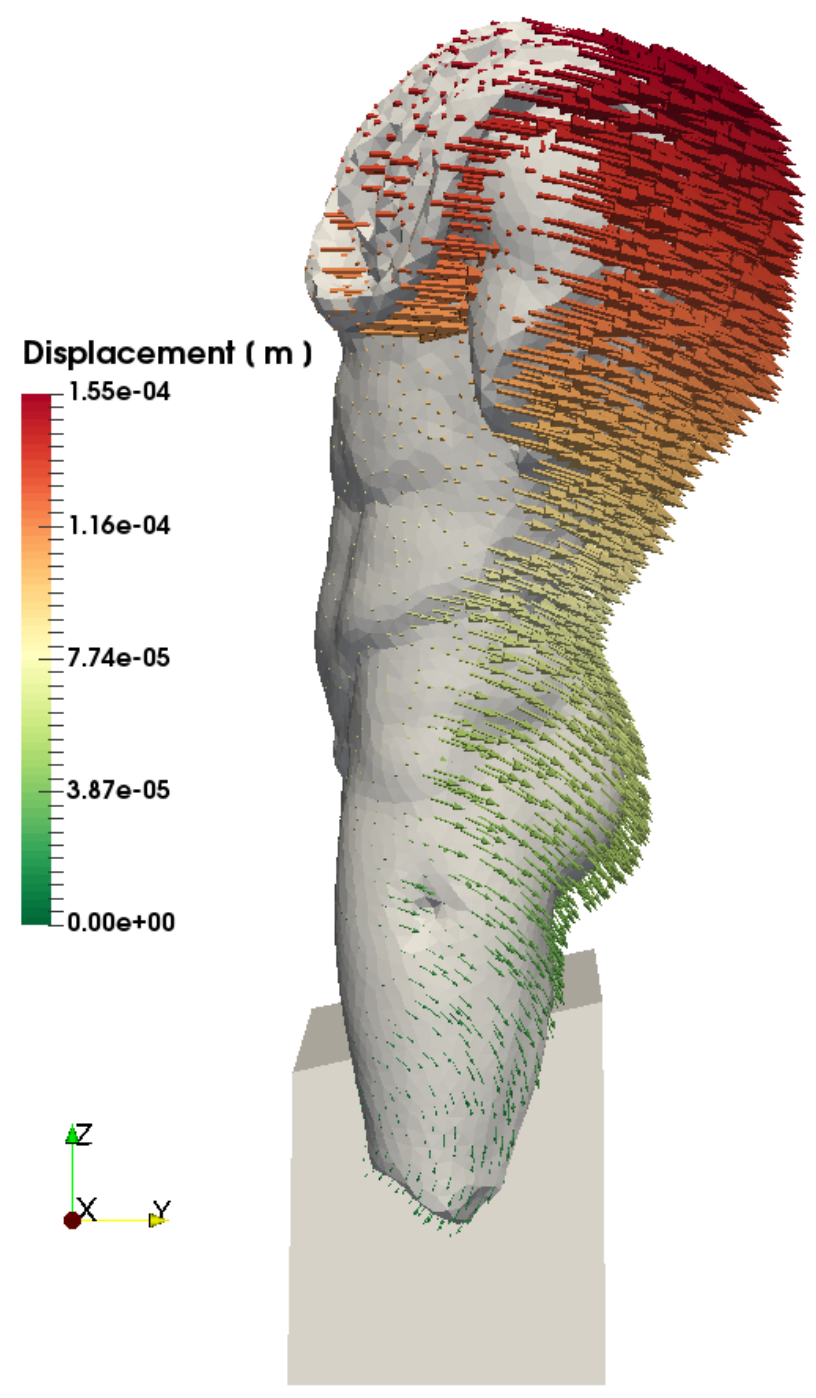

Figure 7: Numerical simulation under gravity load. Displacement of the statue in its base.

Marble is a natural geo-material showing a much larger mechanical strength in compressive conditions rather than in tensile ones. To evaluate the strength when submitted to multi-axial stresses, the Hoek \& Brown criterion is widely used in geotechnical applications [40,41]. According to the maximal and minimal principal stresses, it can be written as a ratio of the most critical stress divided by its corresponding mechanical strength, providing a risk level between 0 and 1 . Under gravity load, the Hoek \& Brown criterion field is shown in Fig. 8. The maximal value is observed at the junction of legs and does not exceed 0.08 , which corresponds to a safety factor of about 12 . Actually, it relates to horizontal tensile stresses generated by the angled surfaces supporting each leg that tend to spread the 
legs apart. Furthermore, the weight of the statue leads to vertical compressive stresses in the left groin which avoid the opening of the visible cracks and prevent their eventual propagation.

Secondly, the critical combination of the gravity load with a $1000 \mathrm{~N}$ horizontal force along the $\mathrm{x}$ direction toward the left side is presented. The distribution of contact pressure at the interface between the statue and the base is shown in Fig. 9. The maximal pressure, now located under the right leg, is about $0.81 \mathrm{MPa}$. The maximal value of the Hoek \& Brown criteria, reaching 0.12 which corresponds to a safety factor of about 8 , is still observed at the junction of legs for the same reasons discussed above.

Globally, this study shows that by relying on a large contact area between the statue and the base $\left(\sim 0.135 \mathrm{~m}^{2}\right)$, displacements and mechanical stresses are relatively low and do not lead to any risk to this masterpiece.
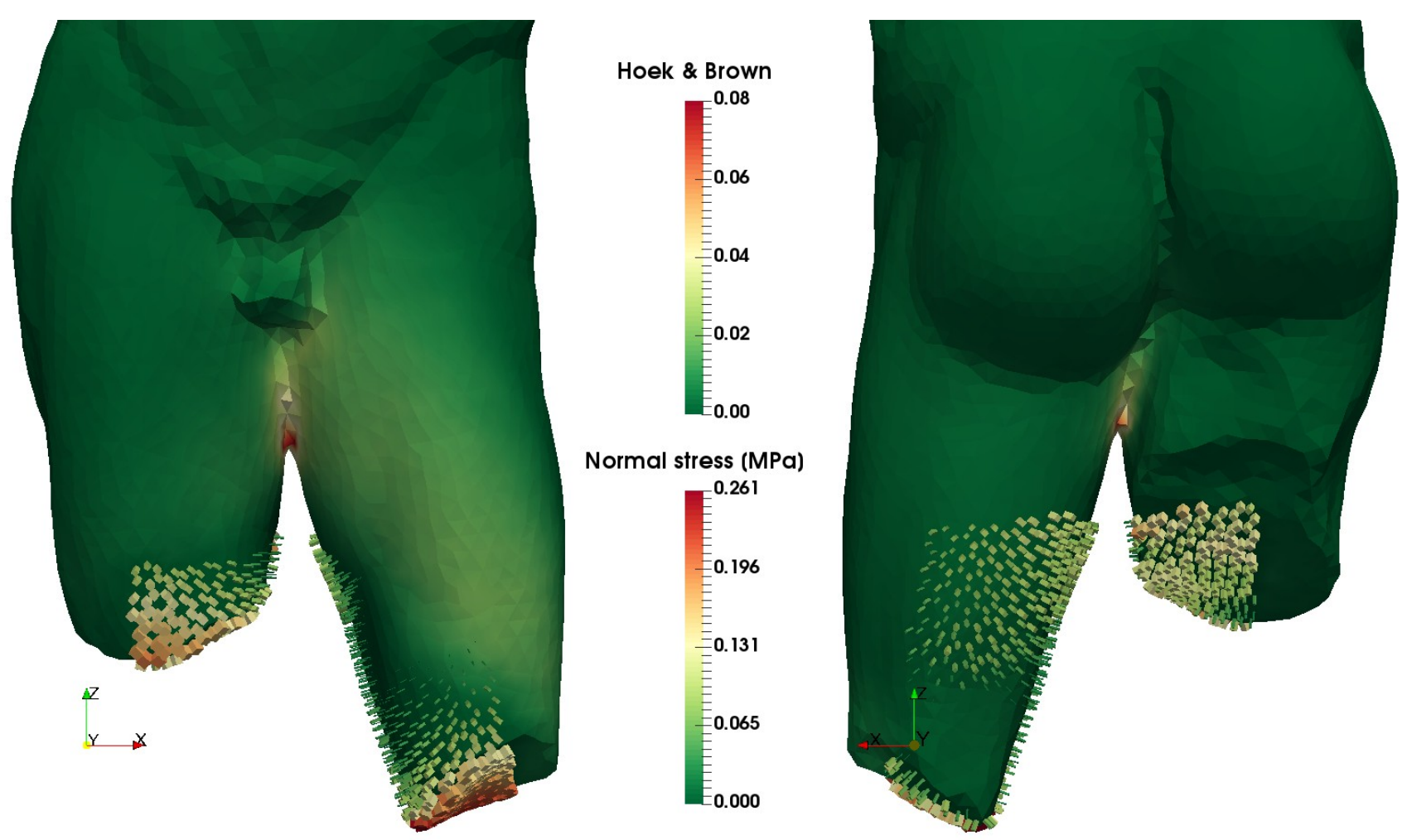

Figure 8: Numerical simulation under gravity load. Distribution of contact pressure at the interface between statue and base - Hoek \& Brown risk level in the statue (visualization with Paraview ). 

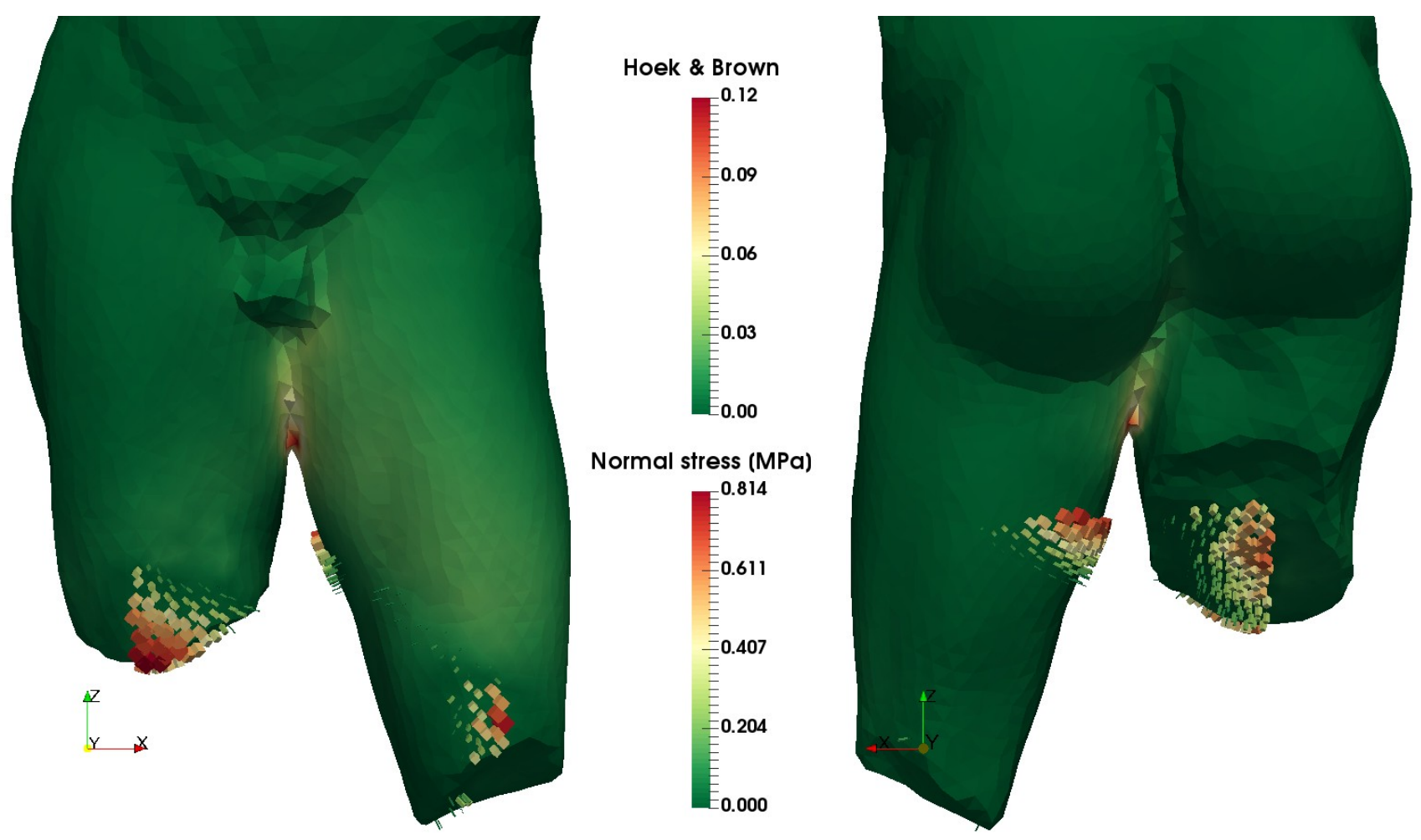

Figure 9: Numerical simulation under gravity load and an accidental horizontal force in the left direction. Distribution of contact pressure at the interface between statue and base - Hoek \& Brown risk level in the statue (visualization with Paraview).

\section{Conclusion}

This paper describes a multidisciplinary methodology aiming at assessing the mechanical behaviour of a marble statue with complex fracture planes and localized cracks. The underlying geometrical data of a 3D model, generated by photogrammetry, provide valuable insight for the physical characterisation and the numerical analysis. Indeed, the ultrasound analysis of a complex shape is achieved thanks to the accurate measures of distance between the transmitter and the receiver obtained from the 3D geometrical model. This approach is a first step into further developments of ultrasound tomography methods that are currently led by some of the authors. Then, the original posture of the statue is recovered by animating a virtual 3D puppet satisfying anatomic constraints. Finally, an innovative use of FEM/DEM analysis is proposed to evaluate the mechanical relevance of a non-destructive basing system. Furthermore, we paid attention to mainly use open-source numerical tools from 3D acquisition 
(MicMac suite tools and MeshLab) through mechanical analysis (Salome, Gmsh, LMGC90 and Paraview) in order to enable the reproducibility of the process. Reflecting the advances of this multidisciplinary work, the resulting solution is non-conventional since it is safe, not intrusive and fully reversible. The minor drawback, associated with the fact that this not intrusive pedestal slightly hides a part of the statue, is worth being paid. Five months were necessary to perform our collaborative approach. The uncommon mechanical analysis entailed various numerical developments which required about $55 \%$ of the overall time. The three other steps, i.e., 3D reconstruction, marble analysis and posture restoration represent $15 \%$ each. For the future, the mechanical analysis step should be compressible.

Actually, the 3D model has not only been used for mechanical purpose. The design process of the base has been done on small scale 3D printed models. When the solution was mechanically validated, a full scale polystyrene model of the statue has been drilled with a CNC machine to help the museum scenography and the final manufacturing of the base. To assess the overall process, a 3D reconstruction could have been done on the final realisation to evaluate the resulting accuracy of this fully computeraided restoration process. However, the proposed methodology conveys further insights to improve the body of heritage and archaeological knowledge, being respectful of the artwork integrity.

\section{Acknowledgements}

The authors acknowledge the help of Emmanuelle Rosso, Assitant-Professor in Roman Art History at the "Université de Paris-Sorbonne”, Martin Szewczyk, Curator for Cultural Heritage at the "Centre de Recherche et de Restauration des Musées de France”. They wish to thank Aude Poinsot, Head of MuséAl (site museum and archaeological site of Alba-la-Romaine) for her support. They are also grateful to Emmanuel Desroches, freelance restorer, and Emmanuel Mylle, Technician of MuséAl, for handling the statue. The Department Council of Ardèche is gratefully acknowledged for its financial support. 


\section{References}

[1] G. López, Poleni’s manuscripts about the dome of Saint Peter’s, in: Proceedings of the Second International Congress on Construction History, Cambridge: CHS, 2006: pp. 1957-1979.

[2] N. Marconi, Technicians and Master Builders for the Dome of St. Peter's in Vatican in the Eighteenth Century: The Contribution of Nicola Zabaglia (1664-1750), in: Proceedings of the 3rd International Congress on Construction History, Cottbus, 2009.

[3] F. Bettio, R. Pintus, A.J. Villanueva, E. Merella, F. Marton, E. Gobbetti, Mont'e Scan: Effective Shape and Color Digitization of Cluttered 3D Artworks, Journal on Computing and Cultural Heritage. 8 (2015) 1-23. doi:10.1145/2644823.

[4] E. Gattet, J. Devogelaere, R. Raffin, L. Bergerot, M. Daniel, P. Jockey, L. De Luca, A versatile and low-cost 3D acquisition and processing pipeline for collecting mass of archaeological findings on the field, International Archives of the Photogrammetry, Remote Sensing and Spatial Information Sciences. XL-5/W4 (2015) 299-305. doi:10.5194/isprsarchives-XL-5-W4-299-2015.

[5] M. Pierrot-Deseilligny, L. De Luca, F. Remondino, Automated image-based procedures for accurate artifacts 3D modeling and orthoimage, Journal of Geoinformatics FCE CTU. 6 (2011). doi:10.14311/gi.6.36.

[6] B.J. Fernández-Palacios, F. Remondino, C. Stefani, J. Lombardo, L. De Luca, Web visualization of complex reality-based 3d models with Nubes, in: Proceedings of Digital Heritage International Congress, IEEE, 2013: pp. 701-704.

[7] A. Sánchez, F. Gómez, A. Martínez, A. Ruiz, M. Molinos, Project 3D-ICONS: The Iberian heritage at the European Digital Library, in: Proceedings of the Second International Congress on Science and Technology for the Conservation of Cultural Heritage, M.A. Rogerio-Candeleria, Sevilla, Spain, 2014: pp. 435-440. 
[8] L. De Luca, T. Driscu, E. Peyrols, D. Labrosse, M. Berthelot, A complete methodology for the virtual assembling of dismounted historic buildings, International Journal on Interactive Design and Manufacturing. 8 (2014) 265-276. doi:10.1007/s12008-014-0224-5.

[9] B. Coignard, D. Hoxha, M. Al Mukhtar, Le Neptune d’Arles : une restauration par simulation informatique préalable, Technè. 38 (2013) 105-111.

[10] C. Riccardelli, M. Morris, G. Wheeler, J. Soultanian, L. Becker, R. Street, The Treatment of Tullio Lombardo’s Adam: A New Approach to the Conservation of Monumental Marble Sculpture, Metropolitan Museum Journal. 49 (2014) 48-116. doi:10.1086/680027.

[11] A. Borri, A. Grazini, Diagnostic analysis of the lesions and stability of Michelangelo's David, Journal of Cultural Heritage. 7 (2006) 273-285. doi:10.1016/j.culher.2006.06.004.

[12] L. Berto, T. Favaretto, A. Saetta, F. Antonelli, L. Lazzarini, Assessment of seismic vulnerability of art objects: The “Galleria dei Prigioni” sculptures at the Accademia Gallery in Florence, Journal of Cultural Heritage. 13 (2012) 7-21. doi:10.1016/j.culher.2011.06.005.

[13] L. Michel, D.P. Do, B. Coignard, D. Hoxha, On the numerical evaluation of historical stone sculpture artwork restoration, European Journal of Environmental and Civil Engineering. 18 (2014) 601-617. doi:10.1080/19648189.2014.891471.

[14] G. Barthe, D. Besnainou, Restauration de l'effigie-portrait de Caïus Ofellius Ferus à Délos, Bulletin de correspondance hellénique. 112 (1988) 413-432. doi:10.3406/bch.1988.1753.

[15] S.K. Kourkoulis, E. Ganniari-Papageorgiou, Restoring fragmented marble epistyles: Some critical points, Journal of Cultural Heritage. 11 (2010) 420-429. doi:10.1016/j.culher.2010.01.002.

[16] L. Michel, D.P. Do, D. Hoxha, B. Coignard, X. Brunetaud, M. Al Mukhtar, Numerical study of the stability of restoring damaged sculpture, in: Proceedings of the 12th International Congress on the 
Deterioration and Conservation of Stone, Columbia University, New York, New York, 2012.

[17] J. Rosewitz, C. Muir, C. Riccardelli, N. Rahbar, G. Wheeler, A multimodal study of pinning selection for restoration of a historic statue, Materials \& Design. 98 (2016) 294-304. doi:10.1016/j.matdes.2016.03.004.

[18] S. Siegesmund, T. Kracke, J. Ruedrich, R. Schwarzburg, Jewish cemetery in Hamburg Altona (Germany): state of marble deterioration and provenance, Engineering Geology. 115 (2010) 200_ 208. doi:10.1016/j.enggeo.2009.07.008.

[19] J. Ruederich, S. Siegesmund, D. Richter, Marble columns and their state of weathering: structural evidence and ultrasonic tomography, German Journal of Geology. 152 (2001) 665-680. doi:10.1127/zdgg/152/2001/665.

[20] J. Ruedrich, C. Knell, J. Enseleit, Y. Rieffel, S. Siegesmund, Stability assessment of marble statuaries of the Schlossbrücke (Berlin, Germany) based on rock strength measurements and ultrasonic wave velocities, Environmental Earth Sciences. 69 (2013) 1451-1469. doi:10.1007/s12665-013-2246-X.

[21] G. Pascale, A. Lolli, Crack assessment in marble sculptures using ultrasonic measurements: Laboratory tests and application on the statue of David by Michelangelo, Journal of Cultural Heritage. 16 (2015) 813-821. doi:10.1016/j.culher.2015.02.005.

[22] J. Dupraz, N. Cossalter, La statuaire antique d'Alba dans son contexte topographique: découvertes anciennes et récentes, Revue archéologique de Narbonnaise. 29 (1996) 93-118. doi:10.3406/ran.1996.1468.

[23] L. Lazzarini, Archaeometric aspects of white and coloured marbles used in antiquity: the state of the art, Periodico Di Mineralogia. 73 (2004) 113-125. 
[24] M. Pierrot-Deseilligny, I. Cléry, Apero, an open source bundle adjusment software for automatic calibration and orientation of set of images, in: International Archives of the Photogrammetry, Remote Sensing and Spatial Information Sciences, 2011.

[25] M. Pierrot-Deseilligny, N. Paparoditis, A multiresolution and optimization-based image matching approach: An application to surface reconstruction from SPOT5-HRS stereo imagery, Archives of Photogrammetry, Remote Sensing and Spatial Information Sciences. 36 (2006).

[26] N. Nony, L. De Luca, A. Godet, M. Pierrot-Deseilligny, F. Remondino, A. Van Dongen, M. Vincitore, Protocols and assisted tool for effective image-based modeling of architectural elements, in: EuroMed 2012, Ioannides M., Fritsch D., Leissner J., Davies R., Remondino F., Caffo R. (eds), 2012: pp. 432-439. doi:10.1007/978-3-642-34234-9_44.

[27] N. Martin-Beaumont, N. Nony, B. Deshayes, M. Pierrot-Deseilligny, L. De Luca, Photographerfriendly work-flows for image-based modelling of heritage artefacts, in: International Archives of the Photogrammetry, Remote Sensing and Spatial Information Sciences, Strasbourg, France, 2013.

[28] I. Toschi, A. Capra, L. De Luca, J.-A. Beraldin, L. Cournoyer, On the evaluation of photogrammetric methods for dense 3D surface reconstruction in a metrological context, in: Remote Sensing and Spatial Information Sciences, Riva del Garda, Italy, 2014.

[29] P. Cignoni, M. Callieri, M. Corsini, M. Dellepiane, F. Ganovelli, G. Ranzuglia, MeshLab: an Open-Source Mesh Processing Tool, in: V. Scarano, R. De Chiara, and U. Erra, 2008.

[30] A. Ahmad, M. Pamplona, S. Simon, Ultrasonic testing for the investigation and characterization of stone - a non-destructive and transportable tool, Studies in Conservation. 54 (2009) 43-53. doi:10.1179/sic.2009.54.Supplement-1.43.

[31] G. Corti, P. Costagliola, M. Bonini, M. Benvenuti, E. Pecchioni, A. Vaiani, F. Landucci, 
Modelling the failure mechanisms of Michelangelo's David through small-scale centrifuge experiments, Journal of Cultural Heritage. 16 (2015) 26-31. doi:10.1016/j.culher.2014.03.001.

[32] F. Dubois, M. Jean, M. Renouf, R. Mozul, A. Martin, M. Bagnéris, LMGC90, in: Actes Du 10ème Colloque National En Calcul Des Structures, Giens, France, 2011.

[33] F. Dubois, M. Jean, The non smooth contact dynamic method: recent LMGC90 software developments and application, in: P. Wriggers, U. Nackenhorst (Eds.), Analysis and Simulation of Contact Problems, Springer Berlin Heidelberg, Berlin, Heidelberg, 2006: pp. 375-378. http://dx.doi.org/10.1007/3-540-31761-9_44.

[34] M. Jean, The non-smooth contact dynamics method, Computer Methods in Applied Mechanics and Engineering. 177 (1999) 235-257.

[35] C. Geuzaine, J.-F. Remacle, Gmsh: A 3-D finite element mesh generator with built-in pre-and post-processing facilities, International Journal for Numerical Methods in Engineering. 79 (2009) 1309-1331.

[36] S.K. Kourkoulis, I. Prassianakis, Z. Agioutantis, G.E. Exadaktylos, Reliability assessment of the NDT results for the internal damage of marble specimens, International Journal of Materials and Product Technology. 26 (2006) 35-56. doi:10.1504/IJMPT.2006.008979.

[37] E. Papamichos, S.-A. Papanicolopulos, I. Larsen, Mechanical properties and damage diagnosis of natural building stones, in: S.K. Kourkoulis (Ed.), Fracture and Failure of Natural Building Stones: Applications in the Restoration of Ancient Monuments, Springer Netherlands, Dordrecht, 2006: pp. 71-92. http://dx.doi.org/10.1007/978-1-4020-5077-0_5.

[38] I.N. Prassianakis, N.I. Prassianakis, Ultrasonic testing of non-metallic materials: concrete and marble, Theoretical and Applied Fracture Mechanics. $42 \quad$ (2004) 191-198. 
doi:10.1016/j.tafmec.2004.08.007.

[39] M. Stavropoulou, Modeling of small-diameter rotary drilling tests on marbles, International Journal of Rock Mechanics and Mining Sciences. 43 (2006) 1034-1051. doi:10.1016/j.ijrmms.2006.03.008.

[40] E. Eberhardt, The Hoek-Brown Failure Criterion, Rock Mechanics and Rock Engineering. 45 (2012) 981-988. doi:10.1007/s00603-012-0276-4.

[41] E. Hoek, E.T. Brown, Practical estimates of rock mass strength, International Journal of Rock Mechanics and Mining Sciences. 34 (1997) 1165-1186. 